\title{
Dynamic changes of circulating vascular endothelial growth factor levels in ST-segment elevation myocardial infarction: Controversies in clinical interpretation
}

\author{
Alexander E Berezin ${ }^{1 *}$ and Alexander A Berezin ${ }^{2}$ \\ ${ }^{1}$ Senior Consultant of Therapeutic Unit, Internal Medicine Department, State Medical University of Zaporozhye, 26, Mayakovsky av., Zaporozhye, Ukraine \\ ${ }^{2}$ Internal Medicine Department, Medical Academy of Postgraduate Education, Zaporozhye, Ukraine
}

\begin{abstract}
The aim of the mini review is discussing the controversial role of vascular endothelial growth factor (VEGF) family members in prediction of clinical outcomes in acute ST segment elevation myocardial infarction (STEMI) patients. Recent studies have shown that high levels of circulating VEGF in STEMI may characterize patients with extensive intracoronary thrombosis, as well as it could associate with favorable clinical outcomes. Although VEGF-A mediated angiogenesis and vasodilation, it was able to promote expression of cell adhesion molecules, such as E-selectin, intercellular adhesion molecule-1, and vascular cell adhesion molecule-1 in surface of endothelial cells, and up-regulated permeability, pro-coagulant activity and inflammation of microvasculature. Yet, exon 8 of VEGF-A gene is involved in the alternate splicing that determines whether the VEGF-A proteins are pro-angiogenic isoform or antiangiogenic isoform of VEGF-A. Moreover, anti-angiogenic potency of VEGF-A165b isoform can influence on developing of adverse cardiac remodeling and plaque rupture. In the review is reported that predictive value of VEGF family member predominantly VEGF-A needs to be investigated in future, because there are several controversial in interpretation of changes in VEGF levels in STEMI
\end{abstract}

Abbreviations: VEGF: Vascular Endothelial growth Factor; VEGFR: VEGF Receptor; PIGF: Placental Growth Factor; MMP: Matrix Metalloprotease.

\section{Introduction}

Vascular endothelial growth factor-A (VEGF-A) is defined as important angiogenic factor, which was found to be up-regulated in acute ST segment elevation myocardial infarction (STEMI) [1]. Circulating VEGF levels in patients with STEMI were significantly higher than in healthy volunteers and it has been demonstrated dramatically decreasing after successful reperfusion with percutaneous coronary intervention [2]. Although VEGF-A mediated angiogenesis and vasodilation, it was able to promote expression of cell adhesion molecules, such as E-selectin, intercellular adhesion molecule-1, and vascular cell adhesion molecule-1 VCAM-1 in surface of endothelial cells, and up-regulated permeability, pro-coagulant activity and inflammation of microvasculature [3]. Overall, there are serious controversies in the interpretation of VEGF dynamic in SEMI. The aim of the mini review is discussing the controversial role of VEGF family members in prediction of clinical outcomes in STEMI patients.

\section{VEGF}

Vascular endothelial growth factor is determined as a family name of manifold factors contributing to angiopoetic effects [4]. In human VEGF-A, -B, -C, D- and placental growth factor (PGF) were identified, while other type of VEGF, such as VEGF-E was also determined in the skin ushering in the Parapoxvirus stimulation and VEGF-F was isolated from Trimeresurus flavoviridis snake venom [5-7]. The main characteristics of VEGFs are reported in Table 1. Noted, all members of VEGF family mediate their biological effect via three types of VEGF receptors (VEGFR-1, VEGFR-1-2 and VEGFR-1-3), which sufficiently distinguished each other in appropriate co-receptors, neuropilins, and compounds of heparin sulfate proteoglycans [8]. The main trigger for VEGF-A production is hypoxia, which promotes synthesis of hypoxiainduced factor-alpha and thereby stimulate releasing of VEGF-A. VEGF-A triggers a migration of mononuclear / macrophages and induces angiogenesis / neovascularization, and vascular permeability [9]. Angiopoetic effect of VEGF-A associates with promoting endothelial progenitor cell proliferation, migration, and survival that leads to accelerating repair after injury. Therefore, VEGF-A stimulates functional activity of monocytes, fibroblasts and mesenchymal stromal cells. Additionally, exon 8 of VEGF-A gene is involved in the alternate splicing that determines whether the VEGF-A proteins are pro-angiogenic isoform or antiangiogenic isoform of VEGF-A [10]. VEGF-B and VEGF-C were found as specific promoters for embryonal angiogenesis as well as lymphangiogenesis and neurogenesis respectively [11-13]. VEGF-D is reported as a trigger for NO release, promoter of capillary-like tube formation and proliferation of endothelial cells [14]. Placental growth factor (PlGF) is expressed in target cells during wound healing and mediates recruitment and migrating endothelial cells,

*Correspondence to: Alexander E. Berezin, Professor, MD, PhD, Senior Consultant of Therapeutic Unit, Internal Medicine Department, State Medical University of Zaporozhye, 26, Mayakovsky av., Zaporozhye, Ukraine, E-mail: aeberezin@gmail.com

Key words: vascular endothelial growth factor, acute ST segment elevation myocardial infarction, endothelium, prognosis

Received: January 15, 2019; Accepted: January 31, 2019; Published: February 02,2019 
Berezin AE (2019) Dynamic changes of circulating vascular endothelial growth factor levels in ST-segment elevation myocardial infarction: Controversies in clinical interpretation

Table 1. Molecular targets and biological effects of the members of VEGF family

\begin{tabular}{|c|c|c|c|c|}
\hline Type of VEGF & Receptors & $\begin{array}{c}\text { Pattern of receptor } \\
\text { specificity }\end{array}$ & Molecular effects in target cells & Biological effects \\
\hline VEGF-A & $\begin{array}{l}\text { VEGFR-1 (Flt-1), VEGFR-2 } \\
\text { (KDR/Flk-1) }\end{array}$ & $\uparrow$ & $\begin{array}{c}\uparrow \text { chemotaxis for mononuclears, } \uparrow \text { vasodilation, } \uparrow \text { capillary } \\
\text { permeability, } \uparrow \alpha \mathrm{V} \beta 3 \text { integrin activity, } \uparrow \text { mitosis and } \\
\text { migration of endothelial progenitor cells, } \uparrow \text { survival of } \\
\text { endothelial cells, } \uparrow \text { chemotaxis of monocytes, } \uparrow \text { functional } \\
\text { activity of fibroblasts and mesenchymal stromal cells, } \uparrow \\
\text { methane monooxygenase activity and MMP }\end{array}$ & $\begin{array}{l}\text { Inducing and supporting angiogenesis / } \\
\text { neovascularization, maintain of tissue repair }\end{array}$ \\
\hline VEGF-B & VEGFR-1 & $\uparrow \uparrow \uparrow$ & $\begin{array}{c}\uparrow \text { mitosis and migration of endothelial progenitor cells, } \\
\uparrow \text { survival of endothelial cells, } \uparrow \text { monocyte migration, } \\
\uparrow \text { inflammatory cytokine production }\end{array}$ & Mediating embryonal angiogenesis \\
\hline VEGF-C & VEGFR-3 & $\uparrow \uparrow$ & $\begin{array}{c}\uparrow \text { mitosis, differentiation, migration and survival of } \\
\text { endothelial progenitor cells }\end{array}$ & Promoting lymphangiogenesis and neurogenesis \\
\hline VEGF-D & VEGFR-3 & $\uparrow \uparrow \uparrow$ & $\begin{array}{l}\uparrow \text { mitosis, differentiation, migration and survival of } \\
\text { endothelial progenitor cells, }\end{array}$ & Developing lymphatic vessels in lungs \\
\hline VEGF-E & VEGFR-3 & $\uparrow \uparrow$ & $\begin{array}{c}\uparrow \text { inflammation and fibrosis, } \uparrow \text { mitosis and differentiation of } \\
\text { keratinocyte, fibroblasts and mononuclears }\end{array}$ & $\begin{array}{l}\text { Promoting keratinocyte function, epidermal } \\
\text { regeneration, re-epithelization and scar tissue } \\
\text { formation }\end{array}$ \\
\hline VEGF-F & VEGFR-3 & $\uparrow \uparrow$ & $\begin{array}{c}\uparrow \text { inflammatory cytokine production, } \uparrow \text { hypocoagulation and } \\
\text { vascular permeability }\end{array}$ & Triggering oedema and vascular permeability \\
\hline PIGF & VEGFR-1 & $\uparrow \uparrow$ & $\uparrow m o n o c y t e$ migration, $\uparrow$ inflammatory cytokine production, & Inducing angiogenesis \\
\hline
\end{tabular}

keratinocytes and as well as monocyte [15]. Viral-expressed VEGF-E enhanced neo-epidermal thickness and wound re-epithelialization through increasing of the number of endothelial cells and blood vessels after binding with VEGFR-2 [16]. Unlike VEGF-A, VEGF-E did not promote expression and activity of matrix metalloproteinase (MMP)2 and MMP-9, while increased expression of some anti-inflammatory cytokines, such interleukin (IL)-10, and reduced macrophage/ mononuclear infiltration and myofibroblast differentiation in wounded skin [17].

\section{Expression of VEGF-A after myocardial infarction}

Previous studies have shown that vascular density begins steadily to increase immediately after myocardial infarction, peaks up at 7 day and then appears to be declined gradually $[4,18,19]$. Although peak levels of VEGF-A mRNA were found at the border zone in 2 hours after developing of myocardial infarction, there was a mishmash between VEGF-A mRNA expression and VEGF-A production. Noted, VEGF-A production in myocardial infarction was persistently suppressed for 12 hours, while over-expressed VEGF-A mRNA was determined for 2 days after event. Interestingly, the expression of VEGF-A both and VEGFR-1/-2 remained unchanged in the non-infarcted myocardium [20]. In fact, the hemodynamic parameters measured serially in peripheral blood were closely related to VEGF-A levels [18]. Therefore, lowered levels of VEGF-A can relate to altered angiogenesis in border zone around of necrotic core shaped after myocardial infarction and thereby mediate extension of the zone through inadequate blood flow reserve [20,21]. Additionally, impaired angiogenesis, exaggeratory inflammatory and fibrotic responses due to deficiency of VEGF-A production plays pivotal role in worsening cardiac repair and scar tissue formation lading to adverse cardiac remodeling [22]. Apparently, hypoxia in border zone has to be a trigger for VEGF-A over-production, and extension of this zone could associated with lower levels of VEGF-A in circulation and VEGF-A mRNA in tissue, while clinical studies regarding developing of adverse cardiac remodeling after myocardial infarction have revealed controversial results, which are being poorly explained traditional approaches toward angiopoetic capacities of VEGF family members. Indeed, on the one hand, activating the VEGF signal cascade associated with increasing vascular permeability, disrupting endothelial tight junctions, promoting tissue edema, inducing thrombus formation, and inflammation. On the other hand,
VEGF system activation leaded to hypocoagulation, angiogenesis, and neovascularization.

\section{VEGF-A levels as predictor of clinical outcomes after myocardial infarction}

Lowered levels of VEGF-A, VEGF-B and PlGF were recently emerged as a predictor of survival and cardiovascular risk in myocardial infarction patients, while increased levels of VEGF-A was found as predictor of intraluminal thrombi [23-25]. Interestingly, the main source for VEGF releasing after myocardial infarction is not fully verified. For instance, activated mononuclears were able to produce VEGF in border zone of infarction, on contrary, platelets were main source for VEGF releasing in the coronary artery wall [25]. Moreover, there were several mishmashes between angiographic figures, hemodynamic parameters after reperfusion and VEGF levels in peripheral blood. In fact, after acute ST segment elevation myocardial infarction (STEMI) increased circulating VEGF-A levels could reflect rather extending intracoronary thrombosis than adverse cardiac remodeling with poor clinical prognosis in follow-up. Recently it has turn out that clinical outcomes in patients after myocardial infarction with adverse cardiac remodeling associated with impaired ration between pro-angiogenic and angiogenic isoforms of VEGF-A [26,27]. Moreover, the complexity and severity of coronary atherosclerosis and shaping of vulnerable atheroma related to predominantly increased expression of anti-angiogenic VEGF-A165b isoform in plaque and in circulation $[27,28]$. Thus, circulating levels of VEGF-A165b are altered after myocardial infarction and might reflect the extent of cardiac damage. Probably, anti-angiogenic isoforms of VEGF-A can suppress migration differentiation and survival of endothelial progenitor cells, which are central players in endogenous vascular repair system [29]. Yet, it can suggest that pro-angiogenic and angiogenic isoforms of VEGF-B / VEGF-C could exist, because proximal / distal splicing is common for each member of the VEGF family. Otherwise it is so hard to explain that results of the ANOX Study. Indeed, in VEGF-C levels were significantly and inversely associated with all-cause death and cardiovascular death, but not with major adverse cardiovascular events (MACE) and cardiac remodeling [30]. Taking into consideration of origin of VEGF-C, MACEs have to be close related to concentration of the biomarker. Thus, changes in VEGF-C levels could reflect other causes related to outcomes in acute STEMI, for example, no-reflow 

interpretation

phenomenon, intracoronary thrombosis, microvascular inflammation with further re-occlusion. In this context, large clinical trials are required to clear explain the possible role of VEGF family members in prediction of clinical outcomes in STEMI.

\section{Conclusion}

High levels of circulating VEGF in STEMI may characterize either patients with extensive intracoronary thrombosis, else with favorable clinical outcomes. Therefore, anti-angiogenic potency of VEGF-A165b isoform can influence on developing of adverse cardiac remodeling and plaque rupture. In this context, predictive value of VEGF family member predominantly VEGF-A, VEGF-C and PlGF needs to be investigated in future, because there are several controversial in interpretation of changes in VEGF levels after STEMI.

\section{Acknowledgement}

This research received no specific grant from any funding agency in the public, commercial, or not-for-profit sectors.

\section{Conflicts of interest}

There are no conflicts of interest.

\section{References}

1. Kranz A, Rau C, Kochs M, Waltenberger J (2000) Elevation of vascular endothelial growth factor-A serum levels following acute myocardial infarction. Evidence for its origin and functional significance. J Mol Cell Cardiol 32: 65-72.

2. Pyda M, Korybalska K, Ksiazek K, Grajek S, Lanocha M, et al. (2006) Effect of heparin on blood vascular endothelial growth factor levels in patients with ST-elevation acute myocardial infarction undergoing primary percutaneous coronary intervention. $\mathrm{Am} \mathrm{J}$ Cardiol 98: 902-905.

3. Suades R, Padró T, Vilahur G, Martin-Yuste V, Sabaté M, et al. (2015) Growing thrombi release increased levels of CD235a $(+)$ microparticles and decreased levels of activated platelet-derived microparticles. Validation in ST-elevation myocardial infarction patients. J Thromb Haemost 13: 1776-1786.

4. Zhao T, Zhao W, Chen Y, Ahokas RA, Sun Y (2010) Vascular endothelial growth factor (VEGF)-A: role on cardiac angiogenesis following myocardial infarction. Microvasc Res 80: 188-194. [Crossref]

5. Oura H, Bertoncini J, Velasco P, Brown LF, Carmeliet P, et al. (2003) A critical role of placental growth factor in the induction of inflammation and edema formation. Blood 101: 560-567. [Crossref]

6. Fleming SB, Wise LM, Mercer AA3 (2015) Molecular genetic analysis of orf virus: a poxvirus that has adapted to skin. Viruses 7: 1505-1539. [Crossref]

7. Yamazaki Y, Matsunaga Y, Tokunaga Y, Obayashi S, Saito M, et al. (2009) Snake venom vascular endothelial growth factors (VEGF-Fs) exclusively vary their structures and functions among species. J Biol Chem 284: 9885-9891.

8. Simons M, Gordon E, Claesson-Welsh L (2016) Mechanisms and regulation of endothelial VEGF receptor signalling. Nat Rev Mol Cell Biol 17: 611-625. [Crossref]

9. Bao P, Kodra A, Tomic-Canic M, Golinko MS, Ehrlich HP, et al. (2009) The role of vascular endothelial growth factor in wound healing. J Surg Res 153: 347-358.

10. Cebe-Suarez S, Zehnder-Fjallman A, Ballmer-Hofer K (2006) The role of VEGF receptors in angiogenesis; complex partnerships. Cell Mol Life Sci 63: 601-615.

11. Nagy JA, Dvorak AM, Dvorak HF (2012) Vascular hyperpermeability, angiogenesis, and stroma generation. Cold Spring Harb Perspect Med 2: a006544.

12. Hagura A, Asai J, Maruyama K, Takenaka H, Kinoshita S, et al. (2014) The VEGF-C/ VEGFR3 signaling pathway contributes to resolving chronic skin inflammation by activating lymphatic vessel function. J Dermatol Sci. 73: 135-141.

13. Bauer SM, Bauer RJ, Liu ZJ, Chen H, Goldstein L, et al. (2005) Vascular endothelial growth factor-C promotes vasculogenesis, angiogenesis, and collagen constriction in three-dimensional collagen gels. J Vasc Surg 41: 699-707.

14. Oura H, Bertoncini J, Velasco P, Brown LF, Carmeliet P, et al. (2003) A critical role of placental growth factor in the induction of inflammation and edema formation. Blood 101: 560-567. [Crossref]
15. Wise LM, Inder MK, Real NC, Stuart GS, Fleming SB, et al. (2012) The vascular endothelial growth factor (VEGF)-E encoded by orf virus regulates keratinocyte proliferation and migration and promotes epidermal regeneration. Cell Microbiol 14: 1376-90.

16. Wise LM, Stuart GS, Real NC, Fleming SB, Mercer AA (2018) VEGF receptor-2 activation mediated by vegf-e limits scar tissue formation following cutaneous injury. Adv Wound Care 7: 283-297.

17. Wynn TA (2008) Cellular and molecular mechanisms of fibrosis. J Pathol 214: 199210. [Crossref]

18. Heba G, Krzeminski T, Porc M, Grzyb J, Dembinska-Kiec A (2001) Relation between expression of TNF alpha, iNOS, VEGF mRNA and development of heart failure after experimental myocardial infarction in rats. $J$ Physiol Pharmacol 52:39-52.

19. Fei L, Zhang J, Niu H, Yuan C, Ma X (2016) Effects of rosuvastatin and MiR-126 on myocardial injury induced by acute myocardial infarction in rats: role of vascular endothelial growth factor a (VEGF-A). Med Sci Monit 22: 2324-2334.

20. Yang F, Liu W, Yan X, Zhou H, Zhang H, et al. (2016) Effects of mir-21 on cardiac microvascular endothelial cells after acute myocardial infarction in rats: role of phosphatase and tensin homolog (pten)/vascular endothelial growth factor (VEGF) signal pathway. Med Sci Monit 22: 3562-3575.

21. Du Y, Ge Y, Xu Z, Aa N, Gu X, et al. (2018) Hypoxia-Inducible Factor 1 alpha (HIF1a)/Vascular Endothelial Growth Factor (VEGF) Pathway participates in angiogenesis of myocardial infarction in muscone-treated mice: preliminary study. Med Sci Monit 24: 8870-8877.

22. Berezin A (2016) Epigenetics in heart failure phenotypes. BBA Clin 6: 31-37. [Crossref]

23. Iribarren C, Phelps BH, Darbinian JA, McCluskey ER, Quesenberry CP, et al. (2011) Circulating angiopoietins- 1 and -2, angiopoietin receptor Tie- 2 and vascular endothelial growth factor-A as biomarkers of acute myocardial infarction: a prospective nested case-control study. BMC Cardiovasc Disord 11: 31-40.

24. Yu CW, Choi SC, Hong SJ, Choi JH, Park CY, et al. (2013) Cardiovascular event rates in patients with ST-elevation myocardial infarction were lower with early increases in mobilization of Oct4(high)Nanog(high) stem cells into the peripheral circulation during a 4-year follow-up. Int J Cardiol 168: 2533-2539.

25. Korybalska K, Pyda M, Kawka E, Grajek S, Breborowicz A, et al. (2011) Interpretation of elevated serum VEGF concentrations in patients with myocardial infarction. Cytokine 54: 74-78.

26. Harada K, Kikuchi R, Ishii H, Shibata Y, Suzuki S, et al. (2018) Association between the ratio of anti-angiogenic isoform of VEGF-A to total VEGF-A and adverse clinical outcomes in patients after acute myocardial infarction. Int J Cardiol Heart Vasc 19: 3-7.

27. Shibata Y, Kikuchi R, Ishii H, Suzuki S, Harada K, et al. (2018) Balance between angiogenic and anti-angiogenic isoforms of VEGF-A is associated with the complexity and severity of coronary artery disease. Clin Chim Acta 478: 114-119.

28. Hueso L, Rios-Navarro C, Ruiz-Sauri A (2017) Dynamics and implications of circulating anti-angiogenic VEGF-A165b isoform in patients with ST-elevation myocardial infarction. Sci Rep 7: 9962. [Crossref]

29. Berezin AE, Kremzer AA (2013) Analysis of various subsets of circulating mononuclear cells in asymptomatic coronary artery disease. J Clin Med 2: 32-44. [Crossref]

30. Wada H, Suzuki M, Matsuda M, Ajiro Y, Shinozaki T, et al. (2018) VEGF-C and mortality in patients with suspected or known coronary artery disease. $J$ Am Heart Assoc 7: e010355. [Crossref]

Copyright: (C2019 Berezin AE. This is an open-access article distributed under the terms of the Creative Commons Attribution License, which permits unrestricted use, distribution, and reproduction in any medium, provided the original author and source are credited. 